\title{
Review of: "Successful countering of tobacco industry efforts to overturn Thailand's ENDS ban"
}

\author{
Gerry Stimson ${ }^{1}$, Charles A. Gardner, Asa Saligupta \\ 1 Knowledge-Action-Change
}

Potential competing interests: Gerry Stimson is a director of Knowledge-Action-Change and has received grants from the Foundation for a Smoke-Free World (FSFW). FSFW is a US nonprofit 501(c)(3) private foundation. Charles Gardner is CEO of the International Network of Nicotine Consumer Organizations which has received grants from FSFW. FSFW had no role in the planning or execution of this review. Asa Saligupta coordinates ENDS Cigarette Smoke Thailand which is an unfunded volunteer group. All authors advocate for safer nicotine products as alternatives to smoking.

Fatal ethical, methodological and evidential flaws.

This paper makes an excellent case study in how not to do research.

The paper purports to show links between a group of consumer advocates, ENDS Cigarette Smoke Thailand (ECST), and Philip Morris Thailand Ltd (PMTL), who it is alleged worked together to oppose the ban on ecigarettes and heated tobacco products in Thailand. The paper also purports to show that Thai tobacco control organisations were successful in countering tobacco industry efforts to overturn the ban.

These claims are not supported by the accompanying data and analysis.

ECST (run by AS, joint-author of this review) is a Facebook page with contributions from harm reduction advocates in Thailand and which has campaigned against the ban on e-cigarettes in Thailand. It is a looseknit, unpaid, volunteer group and not a formal or legal organisation, and mainly comprises ex-smokers who have switched to safer nicotine products. There is no direct or indirect relationship between ECST and PMTL.

Our review finds that the paper contains fatal ethical, methodological and evidential flaws and raises serious questions about scientific integrity, and the peer review and editorial processes at Tobacco Control.

Tobacco Control states that it does not publish papers with glaringly obvious, fatal methodological problems, and that it "Adheres to the highest standards concerning its editorial policies on publication ethics, scientific misconduct, consent and peer review criteria." [i] This paper does not live up to the 
standards of the BMJ (the owners of Tobacco Control) and Tobacco Control, and does not meet the BMJ criteria for research integrity viz: "Integrity in research means conducting and producing research that is honest, rigorous, transparent and open, and undertaken with care and respect."[ii]

The authors are aware of the major weakness of their claims. In the Limitations section they state that the study was: “...unable to identify if there was a direct financial relationship between ECST and PMI [Philip Morris International] or if ECST was a formal part of PMI's IQOS marketing strategy."

If there was no evidence of financial or other links, then the paper is no more than a mishmash of assertions and there is no case for publication.

We complained to the Editor of Tobacco Control (see at the end of this Review) requesting retraction, and to the Research Integrity office at the BMJ, the owner of Tobacco Control. Subsequently small changes in wording were made and this correction note was added:

"Correction notice. This article has been corrected since its publication with several preference of wording changes to ensure the message of the article is clear. The authors would like to clarify that this article does not identify a direct or other formal relationship between ECST and PMTL."

There are two versions of the paper, the first published on $22^{\text {nd }}$ November 2020 (V1) and a corrected version (V2) published on $13^{\text {th }}$ May 2021. The Editor did not inform us of the publication of the corrected version. The Editor would not provide us with details about what textual changes were made between V1 and V2 and these are not provided in V2 . All references in this review, except where noted, are references to V1, which is now unavailable on the Tobacco Control website and the original is attached for the scientific record.

\section{No ethical approval for the study}

Tobacco Control is bound by the ethical guidelines of its owner, the BMJ, the Committee on Publication Ethics (COPE), ${ }^{[i i i]}$ the World Association of Medical Editors (WAME), the recommendations of the International Committee of Medical Journal Editors (ICMJE), ${ }^{[i v]}$ and the World Medical Association Declaration of Helsinki. ${ }^{[v]}$ The BMJ requires ethical approval for all reports of studies submitted to its journals. ${ }^{[v i]}$

The original paper had no statement about ethics approval or exemption. Failure to seek ethics approval, or to justify why it is not required, is not trivial and should be identified by the journal editor at submission. WAME states that if the study is judged exempt from review, a statement from the Institutional Review 
Board or Ethics committee should be required [vii] - a requirement shared also by Mahidol University, the lead author's institution. ${ }^{\text {[viii] }}$

Retrospective ethical approval. Subsequent to our complaint to the Editor, the first author retrospectively applied for research ethics exemption from Mahidol University, which was mysteriously backdated to $25^{\text {th }}$ November, three days after the paper was first published and before we made our complaint.

In our view the BMJ, and the relevant ethics review boards, lack adequate guidance on ethical issues for studies using public domain information from living individuals. The paper amounts to the harassment of a volunteer body - ECST - by well-resourced academics and a well-resourced academic journal. Attacks on consumer and patient groups are unacceptable in any health field, but are especially repugnant in a setting where they may cause risk of reprisals by authoritarian-leaning governments. The paper does not reach the BMJ standard that research is "undertaken with care and respect". [ix]

\section{Biased framing of the research topic}

Readers are entitled to expect a balanced framing of the issues in a paper published as Original Research. The authors are unapologetically antipathetic to tobacco harm reduction and the use of safer nicotine products, and applaud the efforts of Thai tobacco control organisations to resist demands to rescind the ban on the sale of e-cigarettes. The bias is apparent in the two research questions which set the scene: "This paper uses Thailand to address the two questions: (1) What are tactics (sic) that the TI [tobacco industry] and pro--ENDS advocacy groups have employed to pressure the government to overturn the ENDS ban? (2) How has public health successfully countered these tactics?"

Most of the Introduction and the Discussion are framed around the authors' position that bans are best. It is evident in the distorted discussion about Public Health England's assessment of the data on the relative harmfulness of e-cigarettes and tobacco cigarettes, and the presentation of the USA FDA decision to allow IQOS to be placed on the market.

This bias results in the strange selection, use and interpretation of data. For example, many of the statements made by ECST and PMI that are reported in the paper are based on the available scientific literature. Yet the way these statements are presented seeks disingenuously to suggest that these statements might be false. The authors suggest that Thai tobacco control organisations 'corrected' information from those who were in favour of e-cigarettes, and warned the public about the dangers of ecigarettes. 


\section{Methodological considerations}

\section{Association and inference}

A common flaw in epidemiological work is to confuse correlation with causation, a mistake made by the second author which led to a retraction in a peer-reviewed journal. ${ }^{[x]}$ The authors have fallen into the same trap with this paper.

Their fundamental error is in presuming that similar statements and actions made by different organisations indicate that the organisations are related and are working to a shared plan.

Analogies with other areas will indicate the flaw. For example: car manufacturers such as Ford and environmental groups such as Greenpeace have a mutual interest in the uptake of electric cars - Ford because petrol and diesel cars will be phased out, and Greenpeace for the health of the planet. To hint that Greenpeace is funded by, or works in conjunction with, Ford would be ridiculous and probably actionable because of the resultant damage to Greenpeace's reputation.

A similarity of view and action does not mean similarity of motive or joint working. ECST is a pro-vaping organisation, and PMI produces IQOS, a heated tobacco product (HTP). E-cigarettes and HTPs are different products, though both are non-combustible and are included under the same legislation in Thailand. The authors assume that because both ECST and PMI want to reverse the ENDS ban, they are working together and to the same agenda. They are not. ECST is a vaping advocacy group, concerned with reversing the ban on the sale of e-cigarettes in Thailand. PMI wants to reverse the ban on ENDS so that it might market IQOS

- its current priority is the sale of HTPs and it has no current ambitions to market e-cigarettes. The authors are wrong in assuming that ECST and PMI have the same agenda. Both ECST and PMI have an interest in tobacco harm reduction and safer nicotine products - one for personal health reasons, the other for commercial reasons.

Similarity of views and actions does not prove relationships between organisations and individuals. Such assertions would not stand up as evidence in a court of law and should not stand as evidence in the court of social or policy science. This is a fatal methodological flaw and is sufficient for the paper to have been rejected by Tobacco Control.

\section{Rhetoric replaces research method}

The paper does not set out clear methods for data collection and analysis, and the authors' approach bears no semblance to basic social science research methods. Instead, several rhetorical devices are used to give the impression that ECST and PMI worked in association. This tactic employs a slippery language of hints and insinuation. Such methods employed include: 
Parallelism and coincidence: A false parallelism between PMI and ECST is suggested by placing statements from ECST and PMI side-by-side so as to suggest similarity between them. This leads to the absurd conclusion that two separate groups drawing independent conclusions on the same scientific literature is - in the authors' minds - evidence of collusion. The authors also imply that the coincident timing of events is evidence of collusion between PMI and ECST, for example (as quoted from the Discussion):

“ECST began campaigning against the Thai ban in early 2017, the same time PMI began promoting IQOS in Thailand. Since then, ECST worked in parallel with PMI to promote ENDS legalisation."

Language of linkages: A language of linkages suggests joint working between ECST and PMI. Examples include:

“Common messages ECST and PMI used..."

"ECST and PMI Thailand lobbied government to lift the ENDS ban"

"ECST employed standard industry tactics"

"ECST worked in parallel with PMI to promote ENDS legalisation"

"Claims frequently used by ECST and PMI"

"Both ECST and PMI aggressively promoted Public Health England's statement..."

"The link between ECST and PMI..."

"Although ECST and PMI Thailand have continuously worked to revoke the ban..."

"The linkages between the pro-ENDS movement in Thailand"

"Exposing the links between PMI and the nominally independent pro-ENDS organisation, ECST..."

The phrase "nominally independent" was removed from V2 following our complaint.

The title of Table 1 - "Tl lobbying activities to lift the ban on E cigarettes" indicates that ECST is considered part of the tobacco industry. Following our complaint the wording in this table was changed from "TI lobbying" to "Pro-ENDS lobbying".

Pejorative language: The text is scattered with pejorative tabloid language. For example, "front group", "playbook", "aggressively promoted", and "heavily discredited".

"Tobacco industry tactics": The idea of "tobacco industry tactics" is used to organise the data. This is defined as creating front groups, using public relations to promote ENDS, lobbying decision-makers, seeking to discredit tobacco control advocates, and funding research to promote ENDS. ${ }^{\text {[xi] [xii] }}$ 
The concept of "tobacco industry tactics" leads the reader to believe there is something unusual and underhand about the advocacy methods used by the tobacco industry, and it follows that a consumer group that uses these "tactics" is ergo a tobacco organisation.

Most advocacy organisations - whether consumers, NGOs, philanthropic organisations, multilateral organisations or industry - use a similar package of lobbying, networking, media and social media, and research to pursue their aims and objectives. These are the basic advocacy toolkits used by any organisation seeking social or political change, and are recommended by the WHO. ${ }^{[x i i i]}$

Ironically the authors see no similarity between the actions taken by consumer advocates and those undertaken by tobacco control advocates. The term tobacco "tactic" is used only with respect to ECST, and the authors use a more neutral term "actions" to describe activities undertaken by tobacco control organisations.

"Tobacco industry tactics" is a rhetorical, rather than an analytical, tool: by definition, any organisation using such tactics is considered by the authors to be part of or under the control of the tobacco industry.

\section{Evidential considerations}

\section{The claim that "front groups" were created to challenge the Thai legislation is false}

The paper refers to "pro-ENDS advocacy groups" in the plural and suggests the creation of front groups (plural) to reverse the ban on ENDS. Only one "pro-ENDS advocacy group" is actually discussed in the paper - ECST. It is reasonable to ask whether this is casual writing, or a deliberate attempt to confuse the reader that there were several groups created in response to the ban.

There is no evidence in the paper that any "front groups" were created to challenge the ban: the authors are aware that the ECST Facebook page was created in 2014, before the Thai ban on ENDS.

That the authors imply that ECST is a tobacco industry "front group": ECST is actually a loose-knit consumer group. It is a Facebook page with 92,500 followers. A small number of individuals administer the Facebook page. These individuals, on occasion, represent the views of Thai vapers to a wider audience. ECST is not a legal organisation and cannot enter into any agreement with a third party. It does not have a bank account into which any funds could be paid: hence, even if it wished to, it could not operate as a group funded by another organisation.

The allegation of working and financial links between ECST and PMI is false and attested to in the letter from ECST to the Editor of Tobacco Control: "ECST has not received funding from the tobacco industry, nor do our members, who are unpaid volunteers, have any financial ties with the industry." 
There was no reply from the Editor.

\section{The claim that actions of tobacco control groups helped the Thai government to maintain the ban is not supported}

The paper aims to show thatThai tobacco control organisations helped the government to maintain the ban, as indicated in the title "Successful countering of tobacco industry efforts to overturn Thailand's ENDS ban", and the Conclusion is that: "The government's decision [to continue the ban] resulted from the strong commitment and collaboration among Thai tobacco control organisations and their shared vision to protect the public's health from tobacco products." One of the key takeaway messages in the "What this paper adds" section is that: "Strong commitment, good collaboration and prompt responses of Thai tobacco control advocates were fundamental keys to successful countering of tobacco industry efforts to overturn the ENDS ban."

This conclusion is not based on any evidence. That the Thai government did not overturn the ban on ENDS is indisputable, but no evidence is provided that this was as a result of the campaigning work of tobacco control organisations. Investigating this would require a different kind of study. This reflects the shortcoming of the research design. Further evidence (eg. interviews with government officials) would be required to show what, if any, influence the tobacco control organisations had on government policy.

Rival hypotheses about why the government maintained the ban are not considered. However, there is an intriguing hint in the Discussion, which states that: "Legalising ENDS could also boost PMI's market share in Thailand over the Tobacco Authority of Thailand (TOAT, the state-run Tobacco Monopoly), which had not yet engaged in ENDS business because of concern over the ENDS legislation." And continues: "If PMI manages to legalise ENDS, it could dominate the Thai market."

TOAT is the only entity allowed to manufacture tobacco products within the country. Formerly a monopoly, it is now an arm's length state enterprise, operating as an authority under the Ministry of Finance. As a result of ASEAN trade agreements, other companies are now able to import tobacco products. TOAT controls $70 \%$ of the tobacco market and fears inroads from external tobacco companies. ${ }^{[x i v]}$ Company profits are being reduced by a new excise tax structure which came into effect in 2017. TOAT turned over THB70 billion in 2017 - bringing in substantial revenue to the Thai government. ${ }^{[\mathrm{xv}]}$ Market dominance and fear of competition would be a strong contender as an alternate hypothesis as to why the Thai government did not revoke the ban on ENDS, but this is not investigated in the paper.

\section{Failure to investigate equally the roles of tobacco control groups and harm}




\section{reduction advocates}

In an article purporting to discuss the activities of two separate groupings (tobacco control and harm reduction advocates), the reader may expect equally detailed research on both, regarding how both groups are funded, their linkages, their messaging, and their respective activities.

Whilst the Results section has 11 paragraphs on harm reduction advocacy organisations, there is only one paragraph on tobacco control actions. The entire 'evidence' regarding tobacco control actions is a scant 700 words. This is insufficient to support the title of the paper and the conclusions.

Much is made in the paper of the links between harm reduction advocacy groups, including supposed funding linkages. There is no equivalent investigation of the links, including funding streams, of Thai tobacco control organisations. For example, there is no examination of the links between the Thailandbased South East Asian Tobacco Control Alliance (SEATCA) (funded by Bloomberg Philanthropies to campaign against tobacco harm reduction), Action on Smoking and Health-Thailand, the Thai Health Promotion Foundation, the Tobacco Control Research and Knowledge Management Centre at Mahidol, Thai Health Professionals Alliance Against Tobacco, and the Bloomberg-funded Global Centre for Good Governance in Tobacco Control.

\section{False implication that ECST is linked to PMI through other organisations}

The authors try to link ECST to PMI both directly and mediated through other organisations. These mediated links appear in such statements as: "ECST was linked to PMI through INNCO [International Network of Nicotine Consumer Organisations] and FSFW [Foundation for a Smoke-free World]." and "Although it denied any financial relationship with the tobacco industry, ECST was linked to PMI through INNCO and FSFW."

In his blog Stanton Glantz provides an infographic demonstrating the supposed direct and mediated links. This is a methodologically unsophisticated social network analysis. There is no explanation of the nature of any supposed linkages. A network analysis is meaningless unless supplemented by information about communication flows and content, and power relationships. 


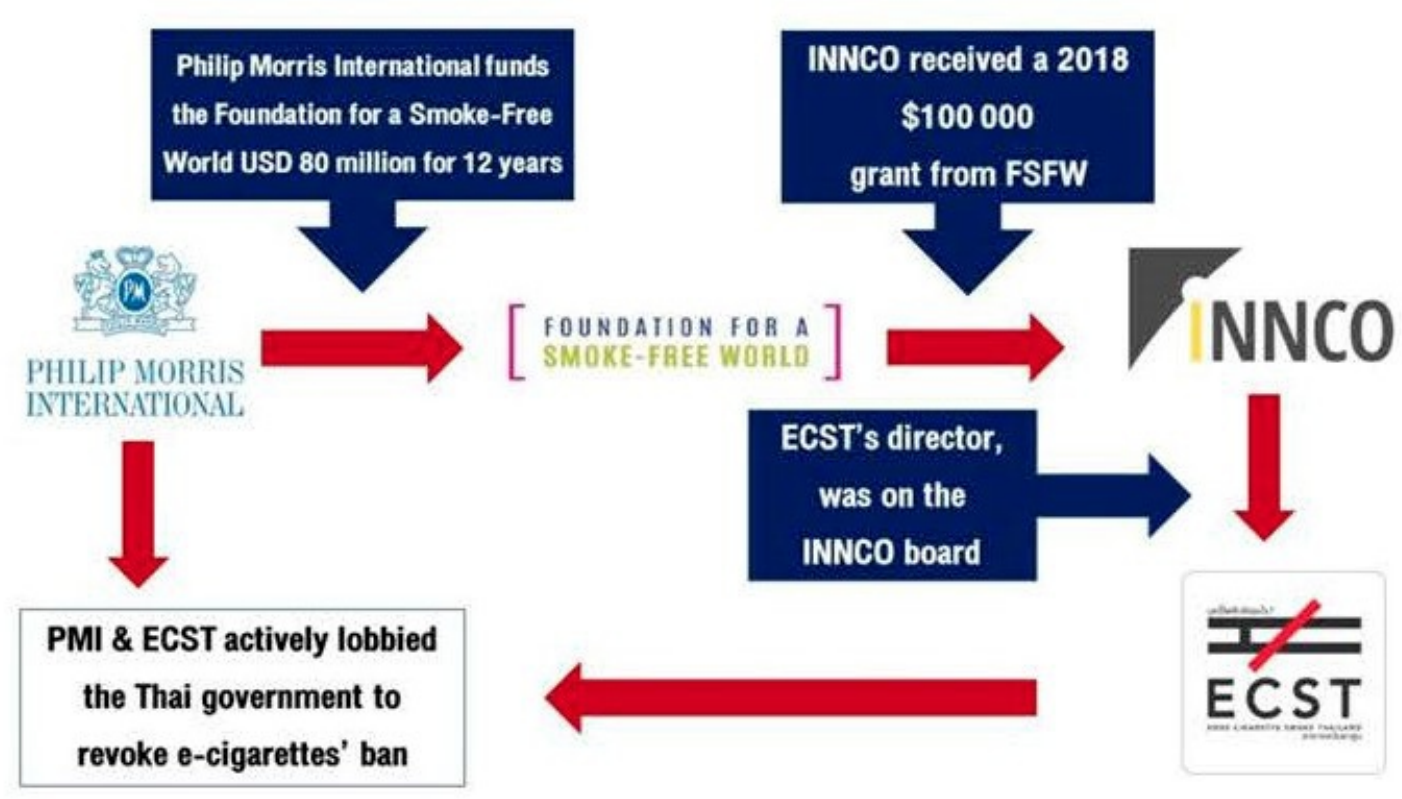

Stanton Glantz believes that there is evidence of an international network linking PMI, FSFW and tobacco harm reduction advocates. He asserts that: "While pro-tobacco forces represent the battle as one of local harm reduction advocates, we found that the pro-ENDS Thai efforts were tied into in (sic) international network that PMI has built with its Foundation for a Smoke-free World as a key facilitating agent (see infographic above)."[xvii]

This is fantasy. Stanton Glantz thinks that PMI has developed an operational structure, using FSFW as the vehicle. It implies a chain of command between PMI and FSFW, and between FSFW and grant-funded organisations. The authors provide no evidence for this. It is indeed implausible given the legal status of FSFW, the legal relationship between PMI and FSFW which guarantees independence of operation, and the contractual relationship between FSFW and grantees.

INNCO made clear to the journal editor, in separate correspondence, that the claim that INNCO has "longstanding ties to the TI" is a fabrication: "INNCO was formed in 2016 when tobacco harm reductionfocused consumer bodies from across the globe joined forces to champion the rights of people who use lower-risk alternatives to combustible tobacco. INNCO's members are autonomous, independent organisations run by consumer volunteers who donate time and efforts to a cause they feel passionately about. These organisations nominate and elect INNCO's Governing Board members, who serve voluntarily without compensation." 
INNCO does not provide operational or support funding to its member organisations, all of whom are distinct, independent, and autonomous bodies. INNCO's role is to enable coordination and cooperation across similar organizations around the world, as well as engaging in targeted national- and regional-level projects.

The statement that "ECST was linked to PMI through INNCO and FSFW" is thus meaningless.

\section{Complaint to BMJ Tobacco Control}

On close analysis the paper falls apart. Publication has, it must be concluded, resulted from inadequate peer review and editorial scrutiny at Tobacco Control.

This review has shown that the paper has irremediable ethical, methodological, analytical, conceptual, and evidential flaws. The findings and conclusions are unreliable. There are numerous other inaccuracies in the paper. A selection is given in the Supplementary Material (attached).

Immediately following the initial publication, ECST and INNCO (and others) submitted Responses to Tobacco Control: these were not published, and a letter of complaint to the Editor, Ruth Malone, was ignored.

Subsequently the authors of this Review submitted a formal complaint and request for retraction on $11^{\text {th }}$ January 2021.

We suggested to the Editor that the article:

- is false and misleading;

- has the potential to damage scientific and public understanding of the field and cause damage to tobacco policy;

- has flawed assertions about links between vaping consumer groups and the tobacco industry;

- will be cited by those who seek to undermine the legitimacy of such groups;

- is damaging to, and places at potential risk, the individuals named in the paper;

- does not meet the BMJ criteria for research integrity. [xviii]

We argued that the fundamental flaws in the paper could not be addressed by minor corrections and that it fulfills the COPE guidelines for retraction, namely that:

Journal editors should consider retracting a publication if:

- they have clear evidence that the findings are unreliable, either as a result of misconduct (e.g. 
data fabrication) or falsification (e.g. image manipulation) or honest error (e.g. miscalculation or experimental error)

- it reports unethical research.

The complaint (substantially this Review article) stated the grounds for retraction were:

- The false claim that several "front" groups were created to challenge the Thai ban on the sale of ENDS;

- The false claim that ECST is a "front" group and/or working hand-in-hand with PMI;

- The misunderstanding of the nature of ECST and the accusation that it is a "front" group;

- The absence of ethical approval, that all allegations are against named people, are defamatory, and place individuals at risk;

- The false conclusions about the role of tobacco control organisations;

- The failure to investigate objectively and equally the two main groupings in the paper (tobacco control and tobacco harm reduction);

- The flawed methodological assumption that supposed network links reflect lines of influence from PMI to vaping advocacy organisations;

- The false imputation of a relationship between ECST and PMI mediated by INNCO.

A long silence from the Editor led us to complain to the Research Integrity office at BMJ. We received the following brief email from the Editor on $24^{\text {th }}$ April 2021:

\section{Dear Prof. Stimson,}

My sincere apologies for the extended delay in responding to your complaint. As you can imagine, investigating a 32 page complaint requires some time and I was awaiting the results of several internal review processes. Your complaint was first reviewed in detail by me and by the deputy editor, then forwarded to the authors of the paper for their responses, which were reviewed again by myself and the deputy editor and additional clarification sought. The original paper, your complaint and the author responses were then reviewed by the BMJ Editor-in-Chief, the Publication Ethics team, and legal advisors, as briefly summarized in an earlier email I believe you received from the Publication Ethics team. These reviews collectively identified several points of clarification that needed to be addressed by the authors, and a correction notice will be published with an amended version of the original paper, making it clear that this article does not identify a direct or other formal relationship between ECST and PMTL. The Rapid Response submissions from the colleagues mentioned in your complaint will also be published shortly and the authors have been invited to respond. I expect the amended paper will be posted next week.

The review did not find grounds for retraction of the paper.

Thank you for your interest in the work published in Tobacco Control. 
Best,

Ruth E. Malone

Editor-in-Chief

We asked for more detail about how our points were addressed, and we received the following response on $11^{\text {th }}$ May 2021:

Dear Prof. Stimson:

Further to your continuing communication about tobaccocontrol-2020-056058, in which you requested additional information about our evaluation of your complaint and those of your cocomplainants, I provide additional information about the main points below.

The relationship between vaping organisations and tobacco industry

We note that the paper stated the groups worked in parallel, not together, using similar messaging, but that indeed the paper clearly stated that no direct financial relationship was identified. However, we did find that in several instances it was reasonable to conclude that such a relationship could be implied. We have required changes throughout the paper to clarify this is not the case, along with a clear statement to this effect.

\section{Research integrity}

We did not find that the paper had "fatal flaws" that would require retraction. The paper is based on review of publicly-available evidence related to a policy decision and focuses on the strategies used to make a case. The paper underwent peer review and subsequently, re-review by the editors, publication ethics and BMJ legal teams.

\section{Ethical approval}

We note that the analysis in the paper is based entirely on evidence from the public record about a policy decision, not on data from human subjects. There was no intervention or interaction with human subjects. However, after this concern was raised to the authors, out of an abundance of caution, Dr. Patanavanich obtained a ruling that the research was exempt from Mahidol University on November 25, 2019.

Ethics issues in use of LINE

We asked the authors about this and they clarified that their analysis was based only on the public parts of LINE.

Allegations against ECST are actually attacks against named individuals

We do not find corroboration of your claim that the paper "attacks" individuals. The only names that are used are those found in public statements in the media, public documents or public websites. Biased framing of the research

No research can legitimately be characterized as completely unbiased or unaffected by the preconceived ideas of a researcher. We find that the paper does answer its research questions, 
although you obviously feel they were not the correct questions to have asked. However, this is true for many types of research. We do not find grounds for retraction on the basis of the research questions. Overall, on careful review we found that many of the claims made in your request for retraction of the paper appeared based on your interpretation of the intentions of the authors, rather than on what the paper actually did or did not state.

Final decision

We will be publishing shortly a correction notice addressing issues identified in our review with an amended version of the original paper, making it clear that the article does not identify a direct or other formal relationship between ECST and PMTL. If your colleagues now do not wish their previously submitted Rapid Responses to be published, they should email me directly and let me know. Upon publication of the amended version of the paper, you or they should feel free to submit a Rapid Response.

Sincerely,

Ruth E. Malone, RN, PhD

Editor-in-Chief, Tobacco Control

\section{Final comment}

It would appear that the Editor of Tobacco Control is content to publish flawed papers. This review raises questions about internal scrutiny of submissions, and about the willingness of the journal to act promptly and comprehensively on complaints.

There is a place for dispassionate and objective social and policy research on both tobacco control and tobacco harm reduction advocacy, but this paper does not evidence such scholarship. It does not reflect well on the academic standing of Tobacco Control. We still find it difficult to understand how such a fatally flawed paper can be published in an academic journal.

\section{References}

[i] Tobacco Control, Authors - Editorial

Policy. https://tobaccocontrol.bmj.com/pages/authors/\#editorial_policy

[ii] BM], Research integrity. https://www.bmj.com/company/researchintegrity/

[iii] Committee on Publication Ethics, Promoting integrity in scholarly research and its publication. https://publicationethics.org/

[iv] ICMJE, Protection of Research Participants. http://www.icmje.org/recommendations/browse/roles-and- 
responsibilities/protection-of-research-participants.html

[v] WMA, WMA Declaration of Helsinki - Ethical Principles for Medical Research Involving Human

Subjects. https://www.wma.net/policies-post/wma-declaration-of-helsinki-ethical-principles-for-medicalresearch-involving-human-subjects/

[vi] BMJ Author Hub, Research Ethics. https://authors.bmj.com/policies/research-ethics/

[vii] WAME, Recommendations on Publication Ethics Policies for Medical Journals - Study Design and

Ethics. http://wame.org/recommendations-on-publication-ethics-policies-for-medical-

journals\#Study\%20Design

[viii] Faculty of Medicine Siriraj Hospital Mahidol University, Institutional Review Board Standard Operating Procedures

(SOP). https://www.si.mahidol.ac.th/sirb/files/\%E0\%B8\%82\%E0\%B9\%89\%E0\%B8\%AD\%E0\%B8\%A1\%E0\%B8 \%B9\%E0\%B8\%A5\%E0\%B8\%AA\%E0\%B8\%B3\%E0\%B8\%AB\%E0\%B8\%A3\%E0\%B8\%B1\%E0\%B8\%9A\%E0\%B8 \%9C\%E0\%B8\%B9\%E0\%B9\%89\%E0\%B8\%A7\%E0\%B8\%B4\%E0\%B8\%88\%E0\%B8\%B1\%E0\%B8\%A2/SOPs_En g.pdf

[ix] BM], Research integrity. https://www.bmj.com/company/researchintegrity/

[x] Retraction to: Electronic Cigarette Use and Myocardial Infarction Among Adults in the US Population Assessment of Tobacco and Health (Journal of the American Heart Association, (2019), 8, 12, (e012317), 10.1161/JAHA.119.012317). Vol. 9, Journal of the American Heart Association. American Heart Association Inc.; 2020. DOI: 10.1161/JAHA.119.014519

[xi] WHO, Tobacco industry interference with tobacco control. https://apps.who.int/iris/bitstream/handle/10665/83128/9789241597340_eng.pdf [xii] Brion J. Fox, Stella Aguinaga Bialous, William M. K. Trochim, Frances A. Stillman, and Carol L. Schmitt, Evaluating Tobacco Industry Tactics as a Counterforce to ASSIST https://cancercontrol.cancer.gov/sites/default/files/2020-06/m17_8.pdf [xiii] Building Blocks for Tobacco Control: A Handbook:https://www.who.int/publications/i/item/9241546581 [xiv] Ross MacKenzie, Hana Ross \& Kelley Lee, 2017, 'Preparing ourselves to become an international organization': Thailand Tobacco Monopoly's regional and global strategies, Global Public Health, 12:3, 351 366

[xv] Thomas Schmid, 28 March 2018, 'Thailand Tobacco Monopoly: Bravely Soldiering On' - interview with TOAT's managing director Daonoi Suttiniphapunt in Tobacco Asia (accessed 8 January 2021).

https://www.tobaccoasia.com/features/thailand-tobacco-monopoly-bravely-soldiering-on/ [xvi] Stanton Glantz, How Thailand successful fought tobacco industry efforts to overturn its ENDS ban https://profglantz.com/2020/11/24/how-thailand-successful-fought-tobacco-industry-efforts-tooverturn-its-ends-ban/

[xvii] Stanton Glantz, How Thailand successful fought tobacco industry efforts to overturn its ENDS ban https://profglantz.com/2020/11/24/how-thailand-successful-fought-tobacco-industry-efforts-tooverturn-its-ends-ban/ 
[xviii] BM], Research integrity, https://www.bmj.com/company/researchintegrity/ 